\title{
A OCUPAÇÃO URBANA DAS MARGENS DO RIO DOCE, EM COLATINA-ES
}

\author{
Rômulo Croce ${ }^{1}$
}

DOI: 10.5752/P.2316-1752.2020v27n40p132

\section{Resumo}

O trabalho propõe investigação acerca da influência da legislação urbanística nas margens fluviais de trecho urbano do Rio Doce inserido em Colatina-ES. Para isso, realizou-se revisão bibliográfica, análise crítica do Zoneamento Urbano e cartografias georreferenciadas. Verificou-se que a legislação não trata de forma adequada as margens do curso d'água, induzindo a altos índices de ocupação, bem como à concentração dos principais empreendimentos imobiliários à beira do rio que, inclusive, utilizam de sua proximidade para aumentar seu valor de mercado.

Palavras-chave: Legislação urbanística. Rios urbanos. Colatina-ES.

1. Arquiteto pelo Ifes Campus Colatina, mestre em Arquitetura e Urbanismo pela UFES. 


\section{THE URBAN OCCUPATION OF THE MARGINS OF RIO DOCE, IN COLATINA-ES}

\begin{abstract}
The work proposes an investigation about the influence of urban legislation in the river margins of the urban stretch of Rio Doce inserted in Colatina-ES. For this, a bibliographic review, critical analysis of the Urban Zoning and georeferenced cartography were carried out. It was found that the legislation does not adequately treat the margins of the watercourse, leading to high occupancy rates, as well as the concentration of the main real estate projects on the riverbank, which even use their proximity to increase their value market share.
\end{abstract}

Keywords: Urban legislation. Urban rivers. Colatina-ES.

\section{LA OCUPACIÓN URBANA DE LAS MÁRGENES DE RIO DOCE, EN COLATINA-ES}

\section{Resumen}

El trabajo propone una investigación sobre la influencia de la legislación urbanística en los márgenes fluviales del tramo urbano de Rio Doce insertado en Colatina-ES. Para ello, se realizó una revisión bibliográfica, análisis crítico de la Zonificación Urbana y cartografía georreferenciada. Se encontró que la legislación no trata adecuadamente los márgenes del curso de agua, lo que lleva a altas tasas de ocupación, así como a la concentración de los principales proyectos inmobiliarios en la orilla del río, que incluso utilizan su proximidad para aumentar su valor. cuota de mercado.

Palabras-claves: Legislación urbana. Ríos urbanos. Colatina-ES 


\section{Introdução}

Em meados da década de 1940, ocorreu, no Brasil, a migração da maior parte da população rural para as cidades (SANTOS, 2009). O controverso processo de urbanização brasileiro foi e ainda é caracterizado pela expansão contínua das cidades e por apresentar padrões de uso e ocupação do solo desordenados, que refletem o insucesso no planejamento de seu crescimento.

A reboque dessa urbanização acelerada, contínua e altamente transformadora da paisagem, emergem inúmeros conflitos sociais e ambientais no território. A população majoritariamente de baixa renda, e que teoricamente não possui condições de adquirir terrenos em locais considerados privilegiados (planos e próximos aos centros urbanos), passa a ter como único destino viável os locais desprezados pelo mercado imobiliário que, muitas vezes, se caracterizam como áreas de fragilidade ambiental, nas quais se enquadram as margens de cursos d'água.

Nesse sentido, junto ao modelo de urbanização rodoviarista e desenvolvimentista implantado, os rios urbanos passaram a ser vistos como meros obstáculos para o crescimento urbano, culminando em uma alteração na relação da cidade com esses elementos. Isso corroborou para que os mesmos sofressem grandes transformações em seus leitos, por meio de processos de retificação e 
canalização, favorecendo a disseminação de prejuízos econômicos, sociais e ambientais para as urbes (GORSKI, 2008; MARICATO, 2000).

É relevante entender que o território brasileiro é caracterizado, em sua quase totalidade, por uma extensa e relevante rede hídrica que desempenhou importante papel nas dinâmicas de configuração espacial desde os primórdios da constituição de assentamentos no Brasil (LIMA; SCHENK, 2016). À medida que as cidades avançam para os territórios fluviais, muitas passam a lhe voltar às costas, o que contribui para que esses elementos se tornem ocultos junto à paisagem urbana.

Dessa forma, faz-se necessário, no processo de planejamento urbano, tratamento específico para os espaços fluviais, entendendo-os como locais de interesse ambiental capazes de engendrar uma série de benefícios para as aglomerações urbanas, sobretudo em sua esfera pública. Para tanto, mostra-se pertinente compreender o curso d'água como elemento constituinte de uma unidade hidrográfica, o que torna indispensável um planejamento que ultrapasse os limites políticos-administrativos, avançando para a escala de bacia hidrográfica.

Destarte, apresenta-se como objeto de estudo empírico as margens urbanas do Rio Doce no município de Colatina-ES, cuja origem de ocupação está intimamente ligada 
ao curso d'água. A escolha do local se deve às constantes transformações que o leito do Rio Doce sofreu não somente no município, mas ao longo de sua bacia hidrográfica, sendo alvo de aterros, implantação de grandes empreendimentos imobiliários, retirada de sua mata ciliar e impermeabilização de seu solo, contribuindo para o agravamento das constantes cheias ocorridas em seu curso. Além disso, o rompimento da barragem de rejeitos da Samarco, em Mariana, em novembro de 2015, evidencia o grande impacto inerente às atividades econômicas desenvolvidas no interior da bacia do Rio Doce, e torna urgente a necessidade de olhar específico para essa problemática na região.

Desse modo, busca-se, no trabalho, de modo mais específico, investigar a influência da legislação urbanística de Colatina-ES, sob a perspectiva de seu zoneamento urbano, nas margens do Rio Doce, em sua porção urbana do município. De modo complementar, discute-se brevemente as transformações históricas das legislações com rebatimentos sobre o espaço fluvial, assim como do conceito de utilização da bacia hidrográfica como unidade territorial de planejamento ambiental e urbano. Ao final, espera-se, ainda, contribuir para o debate crítico acerca da dialética relação entre lei e produção urbana de espaços beira-rio. 


\section{Legislação e áreas de margens de rios: breve contextualização}

Durante o contínuo processo de urbanização ocorrido em território nacional, algo recorrente foi a supressão de áreas ambientais para dar lugar às novas vias, edifícios e, até mesmo, novas cidades. No entanto, o impacto gerado por esse processo avança aos dias atuais, ao passo que diversas cidades brasileiras continuam a expandir seu território, motivadas por interesses ligados, principalmente, ao mercado imobiliário. Áreas de margens de rios, encostas de morros e outras áreas de fragilidade ambiental passam a ser palco de uma crescente ocupação dialética que revelam, de um lado, a dificuldade de inserção da população de baixa renda no mercado formal de habitação e, do outro, a busca pelo "natural" pela população de maior renda, materializada por meio dos condomínios fechados.

Visando a proteção desses locais, também denominados espaços fluviais, e como forma de garantir a manutenção do ciclo hidrológico e biológico natural inerente às Bacias Hidrográficas, foram criadas diversas leis que estabelecem medidas para sua proteção. No âmbito federal, o Novo Código Florestal (Lei n 12.651/2012), define as chamadas Áreas de Preservação Permanente (APP), que se constituem em: com a função ambiental de preservar os recursos hídri- 
cos, a paisagem, a estabilidade geológica e a biodiversidade, facilitar o fluxo gênico de fauna e flora, proteger o solo e assegurar o bem-estar das populações humanas" (BRASIL, 2012).

As APPs estabelecidas pelo Código Florestal (BRASIL, 2012) condizem, ainda, com áreas no entorno de nascentes, encostas com declividade superior a $45^{\circ}$, restingas, manguezais, tabuleiros, chapadas, topos de morro e locais que podem ser definidos como tal a partir de aval do Chefe do Poder Executivo, quando destinadas à função de proteção e manutenção da biodiversidade.

No entanto, importa, para este trabalho, o direcionamento dado à forma como a legislação trata as áreas de margens de rios em ambientes urbanos, entendendo como faixas de extrema importância e que devem ter um tratamento específico durante o processo de planejamento do território urbanizado. Entende-se, também, que as faixas de preservação em sua dimensão ambiental se constituem como importante medida de manutenção dos recursos naturais e que podem contribuir para a qualidade urbana, visto que o bom funcionamento do ambiente urbano está associado a questões de permeabilidade do solo, drenagem e arborização.

Entretanto, corrobora-se com o conceito de autores como Souza e Macedo (2014) e Mello (2012), que entendem que o tratamento de áreas lindeiras a cursos d'água em ambiente urbano deva englobar não apenas aspectos am- 
bientais, mas principalmente as funções características dos espaços livres, como o lazer, a mobilidade e o convívio. Entende-se, portanto, que tais áreas se constituem como parte do sistema de espaços livres urbanos.

A criação das APPs foi estabelecida pela Lei $N^{\circ} 477.1$, de 1965, que instituía o antigo Código Florestal brasileiro e, após sucessivas alterações desta lei, passaram a ser atualmente definidas pelo Novo Código Florestal (Lei $n^{\circ}$ 12.651/2012). Cabe destacar que, desde sua concepção inicial, por meio da legislação, a visão estabelecida às APPs se dá de forma conservacionista, como grande parte das leis ambientais nacionais, revelando uma desarticulação entre interesses ambientais e urbanos.

Como exemplo, o conceito de APP é transposto do contexto rural para o urbano somente ao final da década de 1980, sem haver, todavia, uma efetiva reflexão sobre as condições sociais, culturais e mesmo técnicas, de se criarem medidas específicas, como um conjunto de corredores vegetados. Em uma realidade tão complexa como a existente nas cidades, na qual as pressões sobre o uso do solo são sempre acentuadas, acrescidas de quadros de exclusão social e urbana, e cuja ocupação de grande parte das redes hídricas urbanas é um fato consolidado, é preciso que sejam evidenciadas novas possibilidades de ocupação fluvial, para além da fragmentação entre cidade e meio ambiente (SOUZA; MACEDO, 2014, p. 13). 
A própria Lei $n^{\circ} 12.651 / 2012$ reforça esse processo, ao tratar a dimensão da faixa de preservação para cursos d'água apenas em função de seu leito e ao restringir um vasto leque de uso em seus limites. Cria-se, assim, um impasse entre os interesses urbanos e da própria população de se aproximar do curso d'água e a legislação, que limita esse processo.

O tratamento dado a essas áreas através das legislações ambientais proporciona, ainda, a ociosidade do espaço fluvial urbano que, diante da desigualdade econômica e social presente em grande parte das cidades brasileiras, torna-se alvo de ocupações irregulares que vão desde moradias de famílias de baixa renda, até loteamentos clandestinos e condomínios de alto padrão.

A insuficiência das ações tomadas por parte dos órgãos públicos, que englobam o não planejamento urbano e a falta de fiscalização dessas áreas, contribuiu para que se difundissem modelos de ocupações que não se adequam aos padrões de preservação ambiental necessários a esses locais. Souza e Macedo (2014) também revelam que as restrições legais dificultam a regularização fundiária, bem como a contemplação desses espaços com equipamentos de infraestrutura urbana e práticas ligadas ao saneamento capazes de amenizar os transtornos ambientais ligados a esses modelos de ocupação. 
Em casos considerados de sucesso, ou seja, em que ocorreu a aplicabilidade da legislação por parte do poder público e o incentivo a usos urbanos, tais áreas passaram a abrigar parques lineares, praças, grandes áreas vegetadas e outros tipos de espaços livres. Todavia, levando em consideração uma capacidade de gestão muitas vezes faIha em cidades brasileiras, é comum que tais espaços se apresentem com deficiências estruturais e morfológicas.

Penna (2017) ainda relata que a ausência de diretrizes ligadas às questões urbanas por parte da legislação ambiental ocorre desde a primeira versão do Código Florestal, de 1965. Segundo a autora, somente na Lei 7803/1989 é que existe uma menção às áreas urbanas, porém com as mesmas características das áreas rurais. Além da mencionada lei, com a aprovação da Resolução CONAMA $n^{\circ}$ 369/06, uma nova visão acerca das APPs urbanas passa a ser estabelecida, como a permissão, em casos de interesse público, social e ambiental, da intervenção ou supressão de vegetação nesses espaços.

Apesar dos avanços em termos de legislação ocorridos em território nacional, ressalta-se que a lei continua sendo recurso limitado para tratar essa temática em bacias urbanas, visto que se configura como instrumento de caráter coercitivo e, por isso, se limita a impor restrições ao uso das APPs e a não definir medidas de transformação e indução de novos usos ao território (SOUZA; MACEDO, 
2014).

Torna-se, portanto, necessária a criação de planos de ações específicos para a requalificação das APPs urbanas, assim como das áreas de margens de rios e, para isso, é preciso analisar como estes se inserem no tecido urbano, suas características de conexão com a cidade e seu potencial paisagístico. Assim, é preciso lançar olhar para esses locais e entendê-los como parte do sistema de espaços livres urbanos para que, de fato, tornem alvo de políticas públicas coerentes com suas necessidades.

O tipo de crescimento urbano em curso, principalmente em países da América Latina, tem gerado a necessidade da criação de planos, estratégias e ações voltadas a minimizar os impactos desse processo no ambiente natural. Dessa forma, ressalta-se a importância da formulação de políticas públicas e instrumentos que visem integrar as esferas urbana, ambiental, social e cultural em bacias hidrográficas, sendo necessária nesse processo, uma participação que envolva tanto o poder público, quanto os demais setores da sociedade civil.

\section{0 município de Colatina e a Bacia Hidrográf- ca do Rio Doce}

Apesar do recorte de estudo deste trabalho estar relacionado a áreas lindeiras de rios e tendo, portando, uma escala de análise intra-municipal, ressalta-se a importân- 
cia de se considerar o rio como elemento constituinte estruturador de uma bacia hidrográfica e logo, torna significativo levar em consideração as influências sociais, econômicas e históricas oriundas de outras municipalidades inseridas ao longo de toda essa unidade territorial.

Em sua definição de cunho ambiental, bacia hidrográfica pode ser entendida como uma região definida por divisores de água e topos de morro, onde se escoam as águas captadas através da precipitação, de forma natural. Além disso, possui uma rede de drenagem formada por diversos cursos d'água convergentes para um mesmo ponto de saída, denominado foz ou exutório (ANA, 2006).

Indo além de sua característica associada às questões ecológicas, diversos autores conceituam a bacia hidrográfica como importante unidade de planejamento urbano, como Bernardino, Moura e Araújo (2014), Mello (2008), Gorski (2008) e Moraes e Lorandi (2003), afirmando que o planejamento das cidades não deve se restringir apenas a seus limites políticos e administrativos, sendo de suma relevância a incorporação dos limites físicos e geográficos dessas unidades territoriais, pela função ambiental e hidrológica essencial para atividades biológicas.

A Bacia Hidrográfica do Rio Doce está localizada na região sudeste do Brasil, entre os estados de Minas Gerais e Espírito Santo. De acordo com dados de Coelho (2007), 
a bacia possui extensão total de $853 \mathrm{~km}$, dos quais $86 \%$ pertencem a Minas Gerais e 14\% ao Espírito Santo.

Essa bacia abriga um dos rios de maior importância para o Espírito Santo e para o Leste de Minas e possui atividades ligadas à extração de minério de ferro e de celulose, que são altamente impactantes e transformadoras da paisagem dessa região. A bacia teve sua ocupação consolidada com a implantação da Estrada de Ferro Vitória-Minas, em 1902, alavancando o processo de industrialização (STRAUCH, 1955) e refletindo nas atividades econômicas desenvolvidas em seu território.

Coelho (2007) subdivide a bacia em três Unidades Regionais: Alto, Médio e Baixo Rio Doce. Segundo o autor, essa divisão ocorre devido às características morfoestruturais variadas inerentes à bacia.

A Unidade Alto Rio Doce localiza-se a montante da confluência dos rios Doce e Piracicaba. [...] A Unidade Médio Rio Doce possui seus limites a jusante da confluência dos rios Doce e Piracicaba até a divisa dos estados de Minas Gerais e Espírito Santo. [...] A Unidade Baixo Rio Doce abrange a porção capixaba (COLEHO, 2009, p. 133).

O município de Colatina se insere, portanto, na região do Baixo Rio Doce, pertencendo, também, à região noroeste do Espírito Santo. Possui distância de $135 \mathrm{~km}$ da capital, Vitória, e conta com aproximadamente, 122 mil habitantes (IBGE, 2018). De acordo com definições da ANA 
(2015), Colatina pertence à Bacia Atlântico, trecho leste, sendo parte da sub-bacia do Rio Doce, em seu baixo curso. A cidade teve sua formação e desenvolvimento ligados ao rio de mesmo nome que, por sua vez, a subdivide em duas porções territoriais, uma ao norte e outra, ao sul.
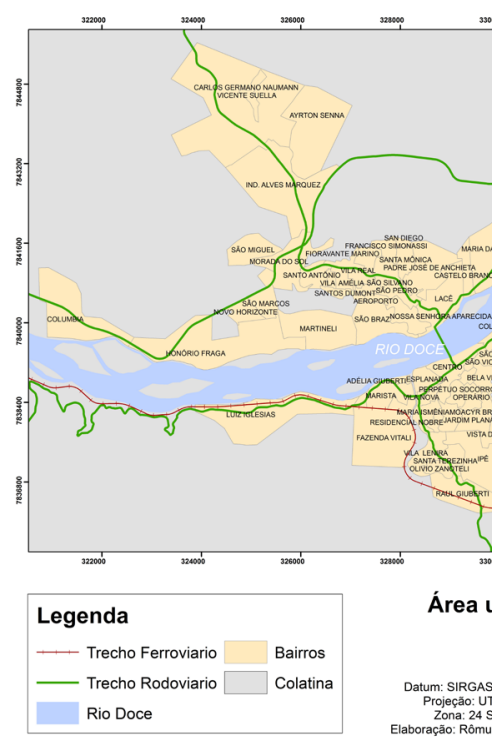
dares, Ipatinga, Coronel Fabriciano e Itabira, um dos seis municípios da bacia com população superior a 100.000 habitantes, conforme pode ser observado na Figura 2. Observa-se que cinco desses municípios se inserem ao longo da malha ferroviária da EFVM, excluindo-se apenas Linhares, localizada junto à foz do rio.

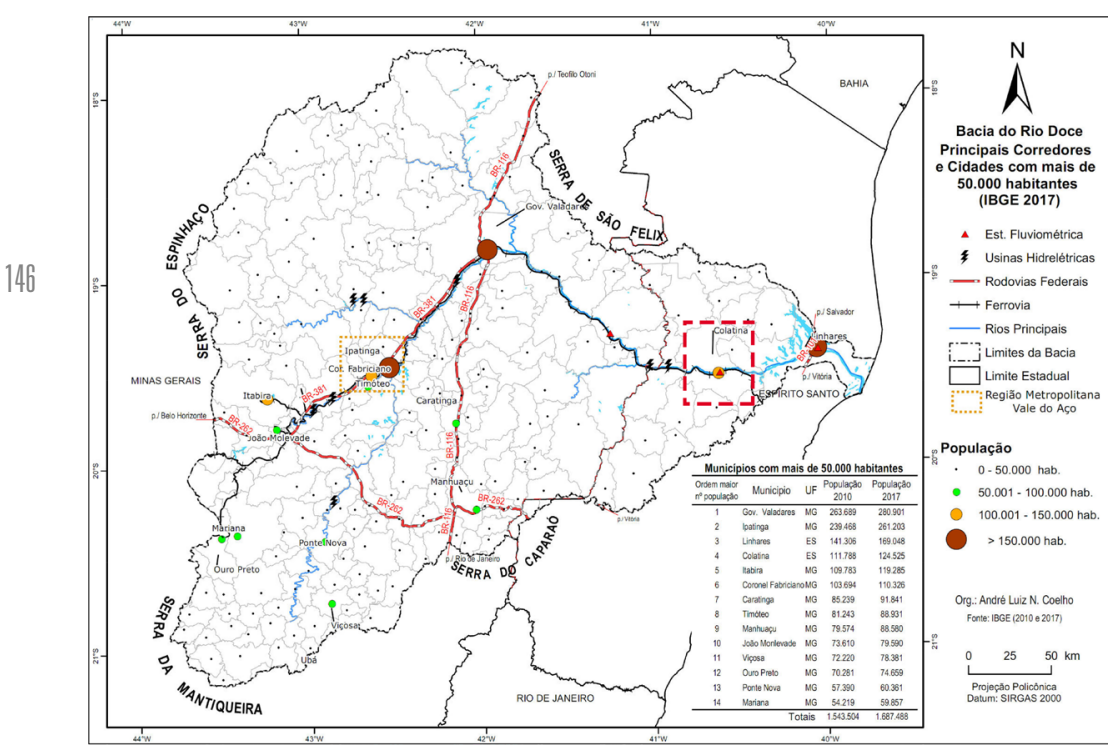

Figura 2 | Bacia do Rio Doce: principais cidades em seu território. Fonte: COELHO, 2009. 
O município pode ser definido como cidade-cruzamento ou cidade-passagem (SIMÕES, 2016), devido sua localização em meio a um entroncamento logístico, além de possuir papel estratégico frente ao fluxo de insumos, especialmente do norte do estado. Nesse contexto, o município teve suas atividades econômicas impulsionadas assim como grande parte das cidades da bacia pelo encontro dos trilhos da EFVM com as áreas lindeiras do Rio Doce.

Ao longo de sua história, conforme mudanças em sua estrutura urbana, a própria relação do município com o Rio Doce também sofreu alterações. Em 1891, ano em que foi fundada a Vila de Colatina, o rio servia como importante meio de acesso a municípios vizinhos, como Linhares (TEIXEIRA, 1974). Posteriormente, passou a ser visto como barreira que impedia fortemente a colonização das terras ao norte do Espírito Santo. Somente em 1928, de acordo com Simões (2016), com a construção da ponte Florentino Avidos, esse "obstáculo" pôde ser ultrapassado e a ocupação urbana avançou pela margem norte do Rio Doce, gerando nova dinâmica de crescimento da cidade.

Nesse cenário, a paisagem do núcleo urbano de Colatina vem sofrendo alterações. Em seus primórdios, era caracterizada como uma paisagem fluvial, marcada pela presença de vegetação nativa capaz de impressionar ex- 
ploradores e os próprios moradores locais.

Em parte alguma do Brasil, nem mesmo no Pará, vi floresta mais exuberante do que a do Rio Doce [...] A floresta forma uma muralha ao longo do rio, tão densa que o olhar não penetra em sua sombra (MALACARNE, 2000, s.n).

Posteriormente, principalmente com a implantação da estrada de ferro e com a ocupação das terras ao norte do município, a paisagem passa a ser definitivamente marcada pela urbanização. Strauch (1955) chama atenção para o fato de que, no início do século XIX, o cenário de intensa extração madeireira culmina na supressão da mata nativa, provocando alteração drástica na paisagem local.

Ao longo dos anos, o processo de extração da vegetação nativa da Bacia do Rio Doce vai ocorrer de forma mais intensa nas adjacências de Linhares a Colatina (STRAU$\mathrm{CH}, 1955)$. Esse fato, aliado às obras de alteração do leito natural do Rio Doce nessa região, contribuíram para a formação de bancos de areia, diminuição de sua lâmina d'água e demais fatores que propiciam, em épocas de maior índice pluviométrico, o transbordamento das águas do rio, formando, assim, enchentes recorrentes em toda a bacia em questão.

A Bacia do Rio Doce se constitui, portanto, como uma região que conserva uma vasta área de equilíbrio ecológico e ambiental vulnerável às dinâmicas de ocupação confli- 
tantes com sua preservação. O estopim desse processo se deu em 2015, através do desastre-crime do rompimento da barragem de rejeitos da Samarco, em Mariana.

Segundo dados da Agência Nacional de Águas (2016), o rompimento da barragem liberou um volume estimado em 34 milhões de $\mathrm{m}^{3}$, composto por rejeitos de mineração, água e materiais utilizados em sua construção, causando uma série de impactos sociais e econômicos na Bacia do Rio Doce.

A onda de rejeitos causou a destruição de povoados próximos à barragem e percorreu grande parte da bacia até atingir o oceano, em um percurso de, aproximadamente, $650 \mathrm{~km}$ (ANA, 2016). Além disso, resultou na morte de 19 pessoas e prejudicou a vida de pequenos agricultores, pescadores, povos indígenas, comunidades ribeirinhas, bem como de boa parte da população urbana e rural à jusante das barragens que dependiam do rio para o desenvolvimento de suas atividades cotidianas.

A ausência de estratégias claras de recuperação ambiental e social por parte das empresas envolvidas, Samarco (Vale/BHP Billiton), e do próprio Estado é algo que ainda perdura aos dias atuais, gerando incertezas sobre a situação futura das comunidades atingidas e do próprio Rio Doce. Tal fato reforça a necessidade de criação e articulação entre planos ambientais e urbanos em nível de 
bacia hidrográfica, capazes de resguardar a sociedade de tragédias como essa.

\section{A legislação urbanística de Colatina e o trata- mento das margens urbanas do Rio Doce}

De modo a investigar a relação entre a legislação urbanística de Colatina e as áreas lindeiras do Rio Doce em seu perímetro urbano, realizou-se análise do Zoneamento Urbano, estabelecido pelo Plano Diretor Municipal (Lei 5.273/2007), por meio do levantamento das diretrizes urbanísticas de ocupação para essas áreas. Para cada zona constante no Plano Diretor para esse trecho, cita-se: taxa de ocupação máxima; taxa de permeabilidade do solo e objetivos específicos dessas zonas que se relacionam com a preservação das margens do rio caso exista.

Utilizou-se como base para a definição das "margens de análise" a definição de APP para o rio Doce estabelecida pelo Novo Código Florestal (BRASIL, 2012), ou seja, um limite de 500 metros de suas margens dentro do perímetro urbano. Para organização das informações, foi elaborada uma tabela síntese (Tabela 1). A Figura 3 apresenta as Zonas que se inserem no recorte estabelecido. Nota-se que 19 Zonas se encontram dentro da área de análise. 


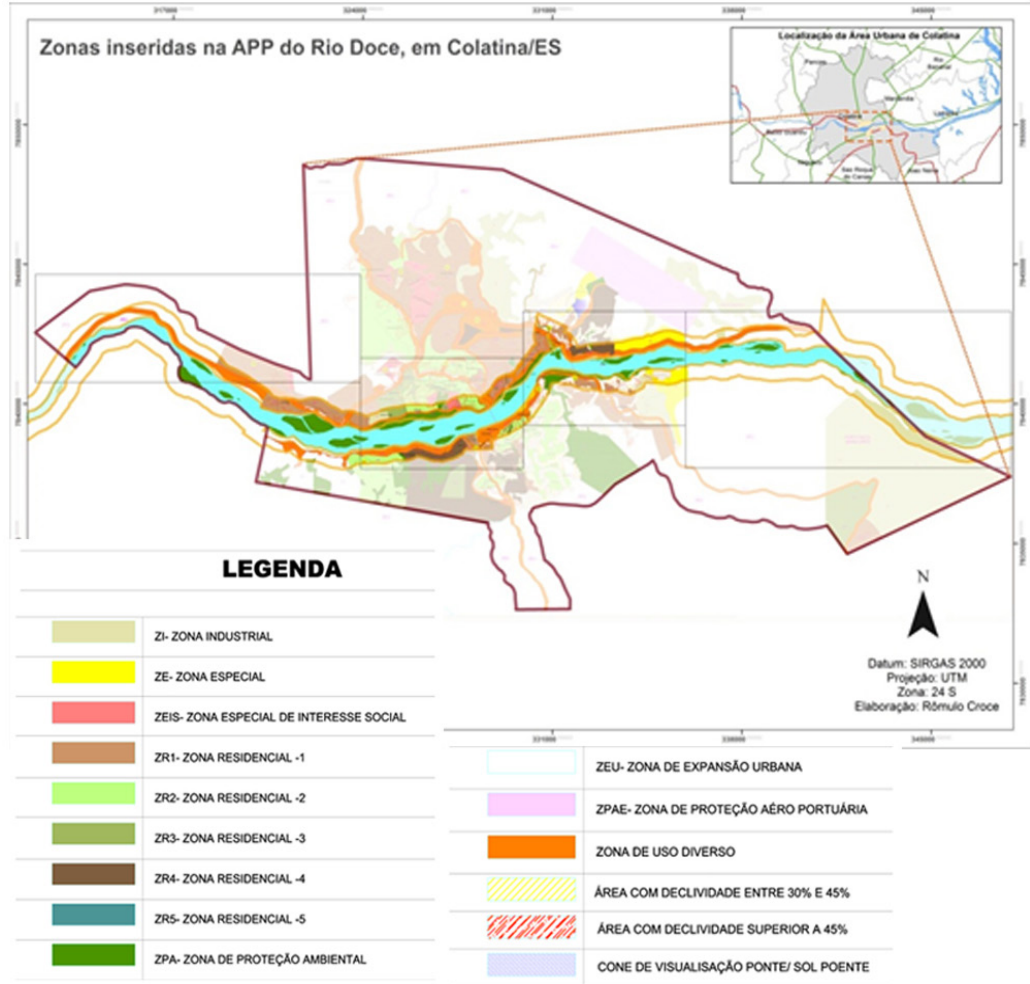

Figura 3 | Mapeamento das Zonas inseridas no recorte de análise. Fonte: Elaborado pelo autor com dados do PDM de Colatina, 2007. 
Observa-se, pela figura, uma heterogeneidade de zonas localizadas às margens do rio, sendo essas com características de ocupação do solo similares as de outros pontos da cidade, o que evidencia a ausência de planejamento e tratamento específico para as margens do rio. Constata-se, também, a baixa quantidade de zonas de Proteção Ambiental (ZPA) junto ao rio, diferentemente das outras zonas, que permitem a ocupação urbana em suas diversas formas e se encontram em maior número.

As ZPAs são as únicas zonas estabelecidas pelo Plano Diretor de Colatina que possuem a função de preservação dos recursos naturais. Entretanto, essas se caracterizam por não estar articuladas a usos urbanos, evidenciando a problemática já levantada por Souza e Macedo (2014), ao definir que as APPs, em território urbano, precisam possuir tratamento distinto das rurais, por se constituírem como parte de seu sistema de espaços livres. Além disso, a maior parte das ZPAs se insere junto às ilhas fluviais do Rio Doce (onde a população não possui acesso) e em locais nos quais, atualmente, ocorrem cultivo de hortaliças e desenvolvimento de atividades ligadas à agricultura familiar, principalmente na margem norte da cidade.

Observa-se uma predominância de Zonas Residenciais (ZR) e, principalmente, Zonas de Uso Diverso (ZUD) no restante da área. As ZUDs se distribuem em locais onde são permitidos usos de comércio, serviços e indústrias de baixo impacto, como o Centro e as principais vias da 
cidade (Figura 4). Além disso, são zonas que possuem índices pouco restritos, incentivando a instalação de empreendimentos imobiliários de grande porte, como hipermercados e shopping centers, o que favorece o capital imobiliário.

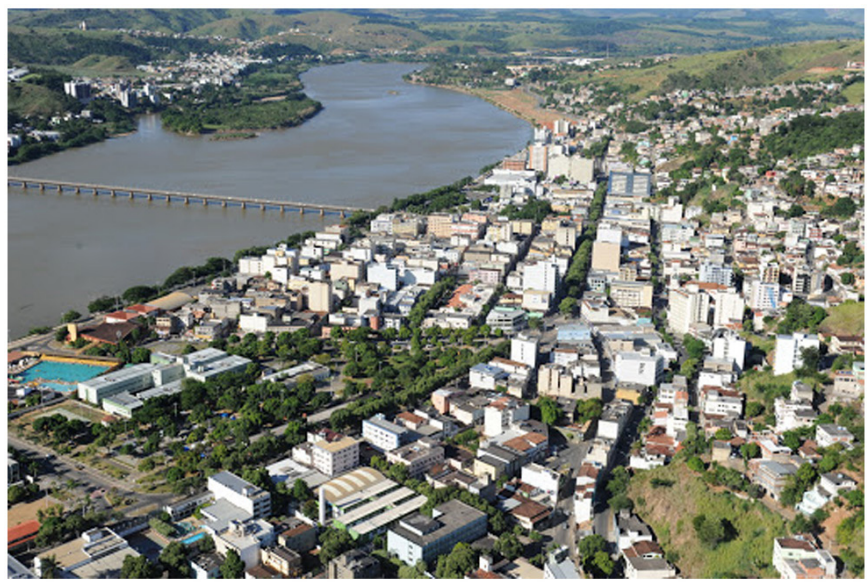

Figura 4 | Vista panorâmica do centro de Colatina

Fonte: Prefeitura Municipal de Colatina.

Destaca-se, também, a presença de Zonas Especiais (ZE) ao longo do aterro da Avenida Beira-Rio, que se constituem como áreas remanescentes do município para as quais não foram estabelecidos critérios de ocupação. É relevante observar que em uma área alvo de sucessivos aterros, passiva de inundações periódicas, não se tenha 
criado nenhuma diretriz de ocupação, tampouco medidas que minimizem os impactos do avanço das águas em período de chuvas mais intensas. Atualmente, ao longo das ZEs, localiza-se uma nova área de eventos a céu aberto, onde corriqueiramente se efetuam atividades esportivas, culturais e de lazer. O local ainda conta com privilegiada visão para o Rio Doce, tornando as práticas listadas anteriormente mais agradáveis. Entretanto, conforme análise feita por Dallapicola (2015), o projeto da Avenida Beira-Rio (Figura 5) para Colatina deve ser observado com olhar crítico, já que, segundo a autora:

[...] essa obra deve ser considerada faraônica para os cofres públicos, e irreversível para os processos geomorfológicos do Doce. E sua efetivação só foi possível com a participação e investimentos do Governo estadual. Contudo, seu objetivo foi frustrado, pois novamente na cheia do Rio Doce em dezembro de 2013, quando este atingiu a vazão de $9.028 \mathrm{~m}^{3} / \mathrm{s}$, a área foi inundada e, por estar em cota maior que as casas, que beiravam o rio, o enrocamento atuou como represa, não permitindo o retorno das águas quando o nível do rio retomou o equilíbrio (DALLAPICOLA, 2015, p. 63). 


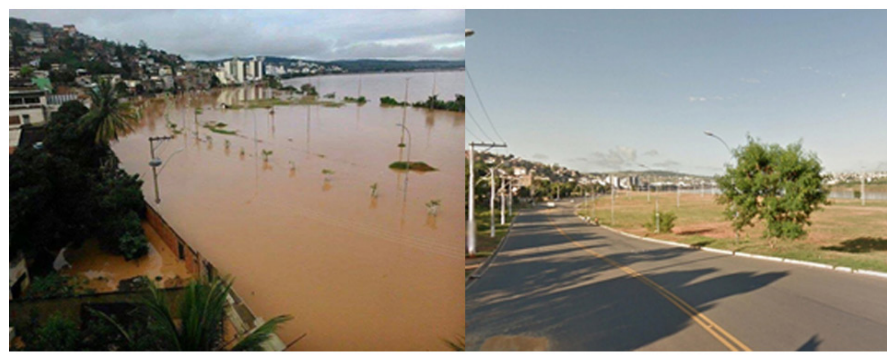

Figura 5 | Avenida Beira-Rio inundada na grande enchente do rio Doce em dezembro de 2013 e sem situação normal, no mesmo ano.

Fonte: Acervo do autor e Google Imagens.

Outras áreas que não possuem critérios de ocupação definidos são as Zonas de Expansão Urbana (ZEU), tratadas pela legislação como grandes áreas desocupadas e por locais passíveis de transformação urbana acelerada. Esses locais não possuem critérios claros de ocupação e são, frequentemente, compreendidos como lacunas na legislação, ocasionando em ocupação segundo os interesses mercadológicos.

A Tabela 1 apresenta, sinteticamente, os índices e parâmetros definidos para cada uma das Zonas que se inserem no recorte definido. Sobre as taxas de ocupação e permeabilidade do solo, fica evidente a permissão de alto índice de ocupação e de baixas porcentagens de áreas permeáveis, principalmente ao longo das ZUDs e ZRs, o que proporciona um aumento contínuo da mancha urbana 
ao longo das margens do Rio Doce.

Além disso, constata-se a ausência de objetivos e diretrizes que visem a integração do próprio rio com essas áreas. As ZPAs se constituem como únicas zonas que possuem diretrizes relacionadas com a proteção das margens do Rio Doce. Contudo, tais objetivos ainda são tímidos e pouco específicos.

O PDM (COLATINA, 2007) não conta com ações claras para a conservação das margens do Rio Doce, tal como para o sistema de espaços livres de Colatina. O plano apenas propõe a criação de parques lineares como diretriz do sistema de drenagem urbana, mas, não especifica o local e nem os responsáveis por sua execução.

Ressalta-se, também, que o PDM está há mais de dois anos sem sofrer processo de revisão, que deveria ter sido realizado em 2017, conforme prazo estabelecido pelo Estatuto da Cidade. 


\begin{tabular}{|c|c|c|c|}
\hline Zona & $\begin{array}{l}\text { Taxa de ocupação } \\
\text { Máxima }\end{array}$ & $\begin{array}{c}\text { Taxa de } \\
\text { permeabilidade }\end{array}$ & $\begin{array}{l}\text { Objetivos que se } \\
\text { relacionam com o } \\
\text { Rio Doce }\end{array}$ \\
\hline ZUD - 1 & $80 \%$ & $10 \%$ & Não possui \\
\hline ZUD - 2 & $80 \%$ & $10 \%$ & Não possui \\
\hline$Z U D-2 / 1$ & $80 \%$ & $10 \%$ & Não possui \\
\hline ZUD - 3 & $75 \%$ & $15 \%$ & Não possui \\
\hline$Z R-1$ & $75 \%$ & $10 \%$ & Não possui \\
\hline$Z R-1 / 2$ & $75 \%$ & $10 \%$ & Não possui \\
\hline$Z R-2$ & $70 \%$ & $10 \%$ & Não possui \\
\hline$Z R-2 / 1$ & $70 \%$ & $10 \%$ & Não possui \\
\hline$Z R-3$ & $65 \%$ & $10 \%$ & Não possui \\
\hline$Z R-4$ & $70 \%$ & $10 \%$ & Não possui \\
\hline ZEIS & Não define & Não define & Não possui \\
\hline $\mathrm{ZPA}-1$ & Não possui & Não possui & $\begin{array}{lr}\text { Define a llha (fluvial) } \\
\text { do Marista } & \text { como } \\
\text { Unidade } & \text { de } \\
\text { Conservação } & \end{array}$ \\
\hline $\mathrm{ZPA}-2$ & Não possui & Não possui & $\begin{array}{l}\text { Define faixa de } \\
\text { proteção de } 50 \\
\text { metros para cursos } \\
\text { d'água que possuam } \\
\text { largura superior a } \\
50 \mathrm{~m} \text { contidos no } \\
\text { perímetro urbano }\end{array}$ \\
\hline $\mathrm{ZPA}-3$ & Não possui & Năo possui & $\begin{array}{l}\text { Define o leito superior } \\
\text { do Rio Doce nas } \\
\text { áreas já ocupadas } \\
\text { pela urbanização } \\
\text { como ZPA }\end{array}$ \\
\hline $\mathrm{ZPA}-4$ & Não possui & Não possui & $\begin{array}{l}\text { Define as ilhas fluviais } \\
\text { do Rio Doce } \\
\text { localizadas nos } \\
\text { limites do município } \\
\text { como ZPA }\end{array}$ \\
\hline ZE & $60 \%$ & Não define & Não possui \\
\hline$Z E-1$ & $60 \%$ & Não define & Não possui \\
\hline
\end{tabular}

Tabela 1 | Síntese dos parâmetros urbanísticos das zonas inseridas na região de estudo. Fonte: Elaborado pelo autor com dados do PDM de Colatina (2007). 
A baixa taxa de permeabilidade exigida pelo PDM para a área, conforme Tabela 1, também se mostra preocupante, pois incide sobre região onde a drenagem já é comprometida devido à expansão urbana sobre o rio. Tais fatos permitem compreender a potencialização das inundações no município, que ocorrem em um intervalo de tempo cada vez menor.

Salienta-se também a faixa de proteção estabelecida para o Rio Doce por meio da ZPA 2. As aprovações de projetos contidos nessa faixa ficam definidas pelo Conselho de Meio Ambiente da Prefeitura Municipal. Não existem critérios claros para a aprovação dos processos que chegam ao conselho, mas, corriqueiramente, são permitidas obras em locais já consolidados e de ocupação nessa faixa que antecede a criação da legislação. A faixa de 50 metros estabelecida pela legislação Municipal é, ainda, exorbitantemente mais permissiva que a Federal (Lei $\mathrm{n}^{\circ}$ 12.651/2012), onde se estabelece faixa de 500 metros para rios do porte do Doce.

Ainda sobre as faixas de proteção do Rio Doce, o Ministério Público Federal, em conjunto com o Ministério Público Estadual, recentemente encaminhou à Prefeitura Municipal a Notificação 004/2018, que recomenda à Secretaria Municipal de Desenvolvimento Urbano e Meio Ambiente de Colatina a abstenção de conceder qualquer autorização para construção e corte/supressão de vegetação na 
APP do Rio Doce, em todo o município de Colatina, na faixa não edificável de 15 metros em cada uma das margens. Ainda não se sabe ao certo os motivos que encabeçam tal notificação. Entretanto, o Conselho Municipal de Meio Ambiente informou que haverá uma reunião com os promotores do Ministério Público para esclarecimentos acerca da medida. Chama atenção o fato de que a medida tenha definido faixa de proteção ainda inferior à estabelecida pelo município, de 50 metros, que por sua vez já se apresenta como insuficiente, diante dos 500 metros exigidos pela lei federal (Figura 6).

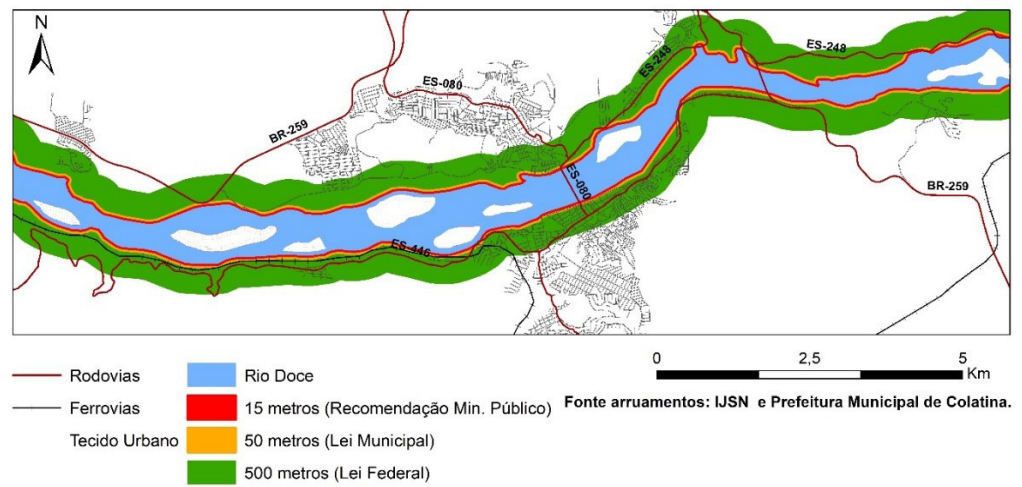

Figura 6 | Comparação entre as faixas de preservação propostas pelas legislações.

Fonte: Elaborado pelo autor. 
Os interesses pela ocupação das margens do Rio Doce, em Colatina, estão fortemente ligados ao mercado imobiliário, sendo que, principalmente ao longo da Avenida Beira-Rio, observa-se um forte processo de verticalização, conforme mostra a Figura 7. A paisagem do rio permanece como valor agregado. O pôr do sol ainda é o principal cartão postal de Colatina. O rio é parte importante dessa paisagem cenográfica (Figura 8) e, mesmo com as toneladas de minério de ferro encravadas em seu leito, bem como as sucessivas inundações que se tornam cada vez mais frequente, suas margens permanecem valorizadas, principalmente nas proximidades do Centro da cidade. 


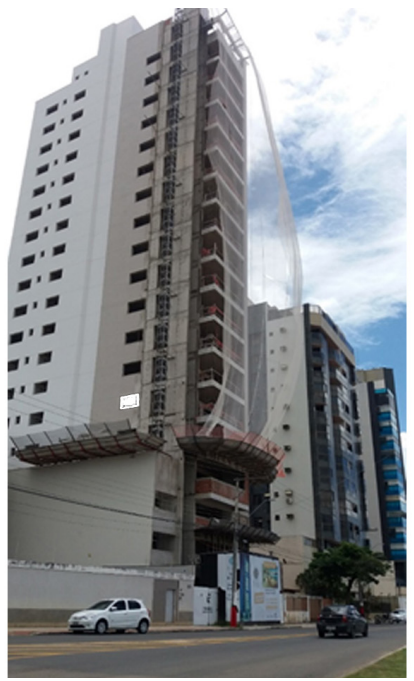

Figura 7 | Processo de verticalização na Avenida Beira-Rio, em Colatina.

Fonte: Acervo do autor.

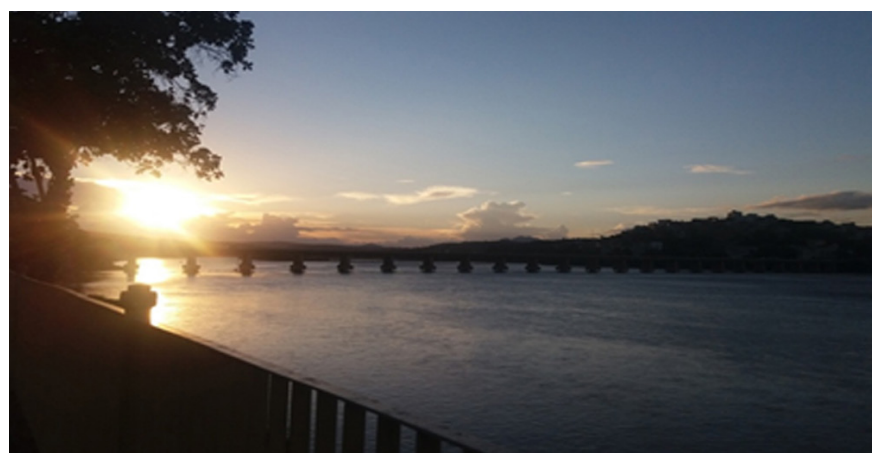

Figura 8 | Pôr do sol, em Colatina, visto às margens do rio Doce. Fonte: Acervo do autor. 
Importante destacar que, no período atual, um conceito muito disseminado no que se refere aos estudos de sistemas fluviais em áreas urbanas é o de renaturalização. Segundo Binder (2001), entende-se como renaturalização a recuperação do ecossistema hídrico, tornando-o o mais próximo possível de sua biota natural, somadas a estratégias de bloqueio de práticas sociais agressivas ao curso d'água. Ademais, o conceito se torna mais complexo que as práticas tradicionais de preservação e recuperação, à medida que propõem práticas mais amplas, que visualizem desde a recomposição dos substratos hídricos e manutenção de suas várzeas inundáveis, à ações que priorizem a utilização de materiais naturais (evitando gabiões, etc.), aliadas à educação ambiental.

Junto a isso, são inúmeros os casos de sucesso, mundo afora, de "reabertura" de rios para cidades e de sua utilização como parte do sistema de espaços livres urbanos. Esse, no entanto, não parece ser o caminho traçado para Colatina, haja vista um iminente cenário de retrocesso que parece se desenhar junto à práxis do planejamento, que tem conduzido sua mancha urbana a avançar cada vez mais para o leito de seu principal rio. 


\section{Considerações finais}

A ausência de planejamento adequado para margens de rios urbanos é algo recorrente não apenas em Colatina, mas também em diversas cidades espalhadas pelo território nacional, fruto de um modelo de urbanização que, historicamente, desprivilegiou áreas de interesse ambiental, entendendo-as como obstáculos para a expansão das cidades.

Ressalta-se que o país teve avanços significativos em termos de legislação ambiental, e isso é evidenciado por meio da criação do Novo Código Florestal (BRASIL, 2012). Todavia, a legislação ainda apresenta falhas, ao deixar de tratar de modo específico das APPs urbanas e dos espaços fluviais, que deveriam receber incentivos para usos relacionados ao lazer e à circulação, impedindo-as de se tornarem áreas conectadas do restante do tecido urbano.

Destaca-se, também, que a simples existência de legislação ambiental ou urbana específica para margens de rios, não se mostra suficiente para garantir a preservação e a potencialização dos usos dessas áreas. Para tal, é de suma importância que tais legislações se articulem de modo a promover equilíbrio entre os interesses ambientais e as necessidades urbanas.

Nesse sentido, torna indispensável um planejamento em nível de bacia hidrográfica, de modo que os planos de 
bacia sejam desenvolvidos de forma integrada aos planos urbanos, garantindo uma gestão urbano-ambiental socialmente justa e sustentável. Além disso, para evitar o avanço da urbanização em áreas lindeiras de rios urbanos, faz-se necessária a implementação de políticas claras e objetivas, de modo a enfrentar, também, as pressões impostas pelo mercado imobiliário e pelo capital especulativo.

Constata-se que as leis e planos existentes em Colatina, evidenciado na definição de zonas heterogêneas, sem medidas específicas, mostram-se insuficientes para o tratamento adequado das margens do Rio Doce em seu território urbano, permitindo urbanização extensiva em suas margens. Essas zonas ainda potencializam a impermeabilização do solo e, consequentemente, favorecem o aumento de inundações no município. A carência de medidas claras de proteção para o Rio Doce no PDM de Colatina também se torna um empecilho para o planejamento de suas margens.

Ressaltam-se, também, as constantes reduções da faixa de proteção para o Rio Doce no perímetro urbano da cidade como algo preocupante. A faixa de proteção estabelecida pelo Ministério Público (15 metros) é ainda mais permissiva que a definida pelo município (50 metros), que já se apresenta inadequada à exigência da lei federal (500 metros), o que pode agravar ainda mais os impactos ine- 
rentes à ocupação urbana nesses locais, caso não seja definido um planejamento harmônico para tal ocupação.

Por fim, faz-se fundamental, tanto para o município de Colatina quanto para os demais municípios da bacia do Rio Doce, a criação de legislação coerente e que busque o tratamento adequado para suas margens. Para subsidiar tais legislações e ações, é preciso que sejam desenvolvidos estudos para esses municípios, levando em consideração suas diferentes inserções urbanísticas ao longo da bacia, bem como suas especificidades. Ainda, é necessário que se olhe para os espaços livres enquanto elementos estruturadores do tecido urbano, capazes de promover maior integração entre a cidade e o próprio rio.

\section{Referências}

ANA - AGÊNCIA NACIONAL DE ÁGUAS. Caminho das águas: conhecimento, uso e gestão. Brasília: ANA, 2006.

ANA - AGÊNCIA NACIONAL DE ÁGUAS. Conjuntura dos recursos hídricos no Brasil: regiões hidrográficas brasileiras: edição especial. Brasília: ANA, 2015.

ANA - AGÊNCIA NACIONAL DE ÁGUAS. Encarte especial sobre a Bacia do Rio Doce: Rompimento da barragem em Mariana/MG. Disponível em: < http://arquivos. 
ana.gov.br/RioDoce/EncarteRioDoce_22_03_2016v2. pdf>. Acesso em: jul. 2018.

ARAÚJO, L. E. de; SOUSA, F. A. S.; MORAES NETO, J. M.; SOUTO, J. S.; REINALDO, L. R. L. R. Bacias hidrográficas e impactos ambientais. Qualit@s Revista Eletrônica, Paraíba, v.8, n.1, p. 1-18. 2009.

BAPTISTA, Márcio; CARDOSO, Adriana. Rios e cidades: uma longa e sinuosa história... Revista UFMG - V.20. Belo Horizonte, 2013.

BERNARDINO, Joice Martins Machado; MOURA, Ana Clara Mourão; ARAÚJO, Rogério Palhares Zschaber de. Uso de geotecnologias na análise de bacias hidrográficas urbanas. In: Anais do XXVI Congresso Brasileiro de Cartografia. Gramado, 2014.

BINDER, Walter. Rios e Córregos: Preservar - Conservar - Renaturalizar. A recuperação de rios, possibilidades e limites na engenharia ambiental. Rio de Janeiro: SEMADS, 2001.

BRASIL. Lei n 4.771, de 15 de setembro de 1965. Institui o Código Florestal. Diário Oficial da União. Brasília, 1965.

BRASIL. Lei $n^{\circ} 7.803$, de 18 de julho de 1989. Altera a redação da Lei $n^{\circ}$ 4.771, de 15 de setembro de 1965, 
e revoga as Leis $n^{\circ}$ s 6.535 , de 15 de junho de 1978, e 7.511, de 7 de julho de 1986. Diário Oficial da União. Brasília, 1989.

BRASIL. Lei n 9.433, de 08 de janeiro de 1997. Institui a Política Nacional de Recursos Hídricos e dá outras providências. Diário Oficial da União. Brasília, 1997.

BRASIL, Lei n 12.651, de 25 de maio de 2012. Dispõe sobre a proteção da vegetação nativa e dá outras providências. Diário Oficial da União. Brasília, 2012.

COELHO, André Luiz. Nascentes. Alterações Hidrogeomorfológicas no Médio-Baixo Rio Doce/ES. 2007. 227 f. Tese de Doutorado (Universidade Federal Fluminense, Instituto de Geociências, Departamento de Geografia), Niterói, 2007.

COELHO, André Luiz Nascentes. Bacia Hidrográfica do Rio Doce (MG/ES): uma análise socioambiental integrada. Revista GeografarES, Vitória - ES, nº7, 2009. P 131-146.

COLATINA (Município). Lei no 5.273, de 12 de março de 2007. Dispõe sobre o Plano Diretor do Município de Colatina e dá outras providências, 2007.

CONSELHO NACIONAL DO MEIO AMBIENTE - CONAMA. Resolução n. ${ }^{\circ}$ 369, de 28 de março de 2006. Dispõe sobre os casos excepcionais, de utilidade pública, in- 
teresse social ou baixo impacto ambiental, que possibilitam a intervenção ou supressão de vegetação em Área de Preservação Permanente-APP. Brasília: DOU de 29/3/2006.

DALLAPICOLA, Maionny Soares Quieza. Desnaturalização do Rio Doce: uma abordagem geográfica das intervenções no setor urbano de Colatina/ES. 2015. $80 \mathrm{f}$. Monografia (Bacharelado em Geografia) - Departamento de Geografia da Universidade Federal do Espírito Santo, Vitória, 2015.

GORSKI, Maria Cecília Barbieri. Rios e cidades: ruptura e reconciliação. Dissertação de Mestrado, FAU-Mackenzie, 2008.

INSTITUTO BRASILEIRO DE GEOGRAFIA E ESTATÍSTICA (IBGE). Cidades. Disponível em: <http://www.cidades. ibge.gov.br/xtras/perfil.php?lang=\&codmun=320150\&search=espiri to-santo|Colatina $>$. Acesso em: jun. 2019.

LIMA, Maria Cecília Pedro Bom de; SCHENK, Luciana Bongiovanni Martins. Rios e cidade: processo de construção da forma urbana de São Carlos, SP. Anais do XI Colóquio QUAPA SEL. Salvador, 2016.

MALACARNE, Altair. São Gabriel da Palha - A história da origem. São Gabriel da Palha: Cricaré, 2000. 
MARICATO, Ermínia. As ideias fora do lugar e o lugar

fora das ideias: - planejamento urbano no Brasil. In: ARANTES, O.; VAINER, C.; MARICATO, E. (Orgs.). A cidade do pensamento único: desmanchando consensos. Petrópolis: Vozes, 2000, p. 121-192.

MELLO, Sandra Soares de. Na beira do rio tem uma cidade: urbanidade e valorização dos corpos d'água. Tese (Doutorado em Arquitetura e Urbanismo), Universidade de Brasília, Brasília, 2008.

MELLO, Sandra Soares. Espaços urbanos em beira d' água. In: SEMINÁRIO DE ÁREAS DE PRESERVAÇÃO PERMANENTE EM MEIO URBANO, 2, 2012, Natal. Anais... Brasília: ANPUR, 2012, p.1-20.

MORAES, Maria Eugênia Bruck de; LORANDI, Reinaldo. Análise da efetividade da legislação ambiental no processo de ocupação de bacia hidrográficas: o caso da bacia do Rio Bonito (SP). Revista Direito Ambiental, São Paulo, v.9, n.36, p.151- 167, 2003.

PENNA, Tainah Virgínia Cypriano. Rios urbanos e paisagem: do convívio à negação em Cachoeiro de Itapemirim-ES. 2017. 193 f. Dissertação (Mestrado em Arquitetura e Urbanismo) - Programa de Pós- - Graduação do Centro de Artes da Universidade Federal do Espírito Santo, Vitória, 2017. 
SANTOS, Milton. A urbanização brasileira. São Paulo: Editora da Universidade de São Paulo, 2009.

SOUZA, Conrado Blando de; MACEDO, Silvio Soares. APPs Fluviais Urbanas e Sistemas de Espaços Livres: O papel da legislação ambiental na configuração do espaço urbano à beira d'água. Anais do $3^{\circ}$ Seminário Nacional sobre o Tratamento de Áreas de Preservação Permanente em Meio Urbano e Restrições Ambientais ao Parcelamento do Solo. Belém, 2014.

SIMÕES, Renata Mattos. A construção de um sistema de espaço livres para Colatina - ES. 2016. 173 f. Dissertação (Mestrado em Arquitetura e Urbanismo) - Programa de Pós- - Graduação do Centro de Artes da Universidade Federal do Espírito Santo, Vitória, 2016.

STRAUCH, Ney. A Bacia do Rio Doce. Rio de Janeiro: IBGE 1955. 199 p.

TEIXEIRA, Fausto. Colatina ontem e hoje [S.I.: s.n.],1974. 